University of Nebraska - Lincoln

DigitalCommons@University of Nebraska - Lincoln

Faculty Publications from the Department of Electrical \& Computer Engineering, Department Electrical and Computer Engineering

3-1-1998

\title{
Studies of metallic multilayer structures, optical properties, and oxidation using in situ spectroscopic ellipsometry
}

\author{
Xiang Gao \\ University of Nebraska-Lincoln \\ Jeff Hale \\ J. A. Woollam Co., Lincoln, Nebraska \\ Scott Heckens \\ University of Nebraska-Lincoln \\ John A. Woollam \\ University of Nebraska-Lincoln, jwoollam1@unl.edu
}

Follow this and additional works at: https://digitalcommons.unl.edu/electricalengineeringfacpub

Part of the Electrical and Computer Engineering Commons

Gao, Xiang; Hale, Jeff; Heckens, Scott; and Woollam, John A., "Studies of metallic multilayer structures, optical properties, and oxidation using in situ spectroscopic ellipsometry" (1998). Faculty Publications from the Department of Electrical and Computer Engineering. 20.

https://digitalcommons.unl.edu/electricalengineeringfacpub/20

This Article is brought to you for free and open access by the Electrical \& Computer Engineering, Department of at DigitalCommons@University of Nebraska - Lincoln. It has been accepted for inclusion in Faculty Publications from the Department of Electrical and Computer Engineering by an authorized administrator of DigitalCommons@University of Nebraska - Lincoln. 


\title{
Studies of metallic multilayer structures, optical properties, and oxidation using in situ spectroscopic ellipsometry
}

\author{
Xiang $\mathrm{Gao}^{\mathrm{a})}$ \\ Center for Microelectronic and Optical Materials Research and \\ Department of Electrical Engineering, University of Nebraska, Lincoln, Nebraska 68588-0511 \\ Jeff Hale \\ J. A. Woollam Co., Inc., Lincoln, Nebraska 68508 \\ Scott Heckens and John A. Woollam \\ Center for Microelectronic and Optical Materials and \\ Department of Electrical Engineering, University of Nebraska, Lincoln, Nebraska 68588-0511
}

(Received 31 January 1997; accepted 21 November 1997)

\begin{abstract}
In situ spectroscopic ellipsometry (SE) has been successfully used to accurately measure sputter deposition rates and optical constants of un-oxidized metal layers and to control the growth of magnetic multilayers. The structures include $[\mathrm{Co} / \mathrm{Cu}]_{\mathrm{n}},[\mathrm{Co} / \mathrm{Au}]_{\mathrm{n}},[\mathrm{Co} / \mathrm{Ni}]_{\mathrm{n}},[\mathrm{Co} / \mathrm{Pd}]_{\mathrm{n}}$ and $[\mathrm{Co} / \mathrm{Pd} /$ $\mathrm{Au}]_{\mathrm{n}}$. Layer thickness precision is better than $\pm 0.05 \mathrm{~nm}$ for layer thicknesses in the range of $0.2 \mathrm{~nm}$ to $10 \mathrm{~nm}$. Closed-loop feedback control of layer thickness is also demonstrated. Good consistency was obtained by comparing the in situ SE results to x-ray diffraction measurements. Dynamic oxidation studies of $[\mathrm{Co} / \mathrm{Au}]_{\mathrm{n}}$ and $[\mathrm{Co} / \mathrm{Ni}]_{\mathrm{n}}$ multilayer structures are also presented. (C) 1998 American Vacuum Society. [S0734-2101(98)02802-4]
\end{abstract}

\section{INTRODUCTION}

Atomically thin metallic multilayers are of special interest as giant magneto-resistance, spin valve, interlayer exchange coupling, and magneto-optic recording media. ${ }^{1-5}$ In all of these applications the thickness of each layer is in the 0.2 $\mathrm{nm}-10 \mathrm{~nm}$ range and requires precise control. X-ray diffraction (XRD) is a popular and accurate method to measure the periodic thicknesses of multilayer structures. ${ }^{6}$ The shortcoming of XRD is that it cannot measure the thickness of the individual layers in multilayers and thicknesses in nonperiodic structures. It would also be difficult and expensive to implement for in situ control. Other methods, such as $\mathrm{x}$-ray fluorescence or weighing the films, can be used to measure individual layer thicknesses in thin multilayers, but they assume that the densities of the thin film layers are the same as bulk materials. Thicknesses are not correct if the roughness of the layers is high or (and) the media oxidizes rapidly. Also, for ex situ methods the sample must be removed from the preparation chamber, and this is time-consuming.

In this article, we describe the use of a diode array-based, rotating analyzer spectroscopic ellipsometer that takes data approximately every second. ${ }^{7}$ As the sputter rates were on the order of $0.1 \mathrm{~nm}$ per sec, precise in situ monitoring of layer thickness and optical constants was possible. We also describe a position and temperature controlled platen for positioning samples over one of four magnetron sputter guns used in thin metallic multilayer formation. That is, in our system, up to four different materials can be selected under computer control for making the multilayer structure, and the sputter deposition rate is accurately determined for each material. Here, we present in situ spectroscopic ellipsometry (SE) investigations of $[\mathrm{Co} / \mathrm{Ni}]_{\mathrm{n}},[\mathrm{Co} / \mathrm{Pd}]_{\mathrm{n}},[\mathrm{Co} / \mathrm{Au}]_{\mathrm{n}}$,

${ }^{\text {a)} E l e c t r o n i c ~ m a i l: ~ x g a o @ e n g r s . u n l . e d u ~}$
$[\mathrm{Co} / \mathrm{Ni} / \mathrm{Au}]_{\mathrm{n}}$, and $[\mathrm{Co} / \mathrm{Pd} / \mathrm{Au}]_{\mathrm{n}}$ multilayers used later for magneto-optic measurements, and $[\mathrm{Co} / \mathrm{Cu}]_{\mathrm{n}}$ used for interlayer magnetic coupling studies.

Oxidation of metallic layers in single films and multilayers is frequently a problem as it introduces an often unwanted layer and it changes the optical, magneto-optical, and other magnetic properties. In this article, we also present results of oxidation studies of $[\mathrm{Co} / \mathrm{Au}]_{\mathrm{n}}$ and $[\mathrm{Co} / \mathrm{Ni}]_{\mathrm{n}}$ structures using in situ SE.

$\mathrm{X}$-ray diffraction measurements were taken on $[\mathrm{Co} / \mathrm{Au}]_{\mathrm{n}}$ multilayer films to verify the in situ SE results. Good consistency was obtained, and the difference between these two methods is better than $3 \%$.

\section{THEORY AND EXPERIMENT}

The metallic thin films and multilayers used for this work were made by magnetron sputter deposition. The base pressure of the sputter chamber was below $3 \times 10^{-7}$ Torr. Both $\mathrm{DC}$ and RF sources were used to generate the plasma. Four sputter guns can be used at the same time, and they are located symmetrically on the bottom of the chamber (Fig. 1a). The substrate wafers on which the films were deposited are fixed in holders on a rotating platen in a sputter-up configuration. There are a total of eight sample holders on the platen, and each sample can be rotated to a position where it directly faces towards the desired sputter gun. There is a shutter for each holder which only opens during growth of the desired host sample. For cases when more than one material is used during growth, such as for making multilayers, the rotation of the platen can be computer controlled in order to turn the sample directly above the relevant sputter gun for different material designs and for precisely controlled deposition times. The software for control coordinates the posi- 


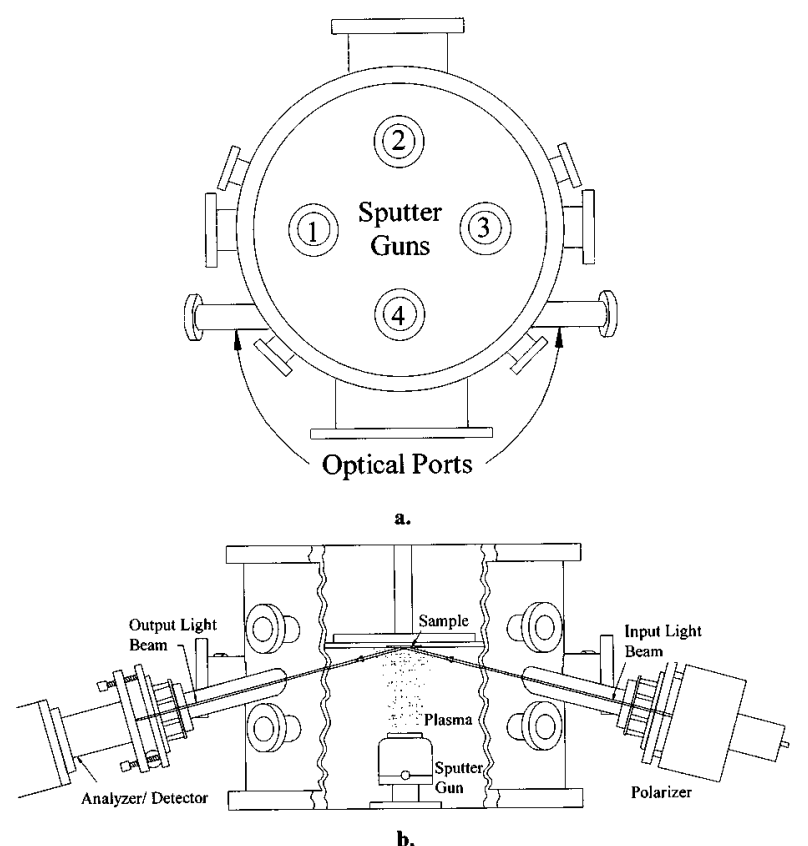

FIG. 1. (a) Top view showing the location of the sputter guns. (b) Side view of the 44 wavelength spectroscopic ellipsometry system.

tion of the sample with data acquisition from the spectroscopic ellipsometer used for in situ calibration of sputter rates and monitoring of sample growth.

The configuration for the ellipsometer optical ports is shown in Fig. 1b. Ellipsometric data can be taken from the sample when it is directly above the sputter gun denoted as No. 4. A collimated light beam passes through a polarizer and through a window on the wall of the sputter chamber and reflects from the sample above gun 4, as seen in Fig. 1b. The reflected beam passes through a second window and is detected by a combination of rotating analyzer and detector for measuring the ellipsometric parameters. The narrow and collimated ellipsometric light beam is not in the direct line of sight with the plasma. Thus, neither the plasma light nor sputtered material interferes with the ellipsometer.

The ellipsometric parameters $\rho$, or $\Psi$ and $\Delta$, is given by ${ }^{8}$

$$
\rho \equiv \tan (\psi) e^{i \Delta}=\frac{R_{P}}{R_{S}},
$$

where $R_{p}$ and $R_{s}$ are sample complex reflection coefficients for light polarized in the " $p$ " and "s" directions (parallel and perpendicular to the plane of incidence, respectively).

A total of eight samples can be loaded on the platen which can rotate under the control of the stepper motor. A computer program was written to control the precise movement of the stepper motor. When the sample for growth is above gun 4 , the program can command ellipsometric data to be taken.

The spectral range of the ellipsometer contains 44 wavelengths from $415.5 \mathrm{~nm}$ to $753.5 \mathrm{~nm}$. As little as $0.04 \mathrm{sec}$ is needed to acquire one set of data simultaneously at all 44 wavelengths. However, acquisition times of $1 \mathrm{sec}$ are normally used, as this is typically the time needed for deposition of a monolayer of material. This amount of data can also be regressed within the $1 \mathrm{sec}$, allowing for closed-loop feedback control when desired.

Data can be displayed as $\Psi$ and $\Delta$, or pseudo-optical constants $\langle\mathrm{n}\rangle$ and $\langle\mathrm{k}\rangle$ which are the complex optical constants of the sample assuming that it is a single substrate with no overlayer. The relationship between pseudo- $\langle\mathrm{n}\rangle$ and $\langle\mathrm{k}\rangle$ to $\rho$ [see Eq. (1)] is given by

$$
\langle n+i k\rangle=\sqrt{\sin ^{2} \phi_{0}\left[1+\tan ^{2} \phi_{0}\left(\frac{1-\rho}{1+\rho}\right)^{2}\right]},
$$

where $\phi_{0}$ is the angle of incidence. In our experiment, $\phi_{0}$ is set close to $75^{\circ}$.

$\Psi$ and $\Delta$ are calculated assuming a model containing layers with flat parallel interfaces on a substrate. Data are a function of the optical constants, the thickness of each layer, and the incident angle $(\phi)$. They also depend on the known wavelengths of the measurement. With initial estimates for the unknown layer thickness and/or optical constants and/or angles of incidence, $\psi$ and $\Delta$ are computed for all wavelengths. The Levenberg-Marquardt algorithm is used to vary the model parameters to minimize the biased estimator $\sigma_{\mathrm{b}}$ (weighted mean square difference between calculated and measured values) given by Eq. (3) to accomplish the model fits. ${ }^{9}$

$$
\sigma_{\mathrm{b}}=\frac{1}{2 n-m-1} \sum_{i=1}^{n}\left\{\frac{\left(\Psi_{i}^{m} \Psi_{i}^{c}\right)^{2}}{\sigma_{i}^{\Psi^{2}}}+\frac{\left(\Delta_{i}^{m}-\Delta_{i}^{c}\right)^{2}}{\sigma_{i}^{\Delta^{2}}}\right\} .
$$

Here $n$ is the number of the experimental data points and $m$ the number of variable parameters.

Spectroscopic ellipsometry has been proven to be an excellent technique for the optical and structural characterization of thin films, and in situ SE has distinct advantages for studies of ultra-thin films. ${ }^{710-12}$ A few specific advantages of in situ SE are the following.

(1) Optical constants of films are directly measured without the effects of oxidation.

(2) Ex situ SE analysis is often limited by mathematical correlation of variables. This problem is greatly reduced when SE is done in situ.

(3) Growth rates for different materials on different substrates can be determined.

(4) Real time monitoring of thin film growth saves the enormous post-growth analysis time normally needed to reproducibly make structures with desired properties.

(5) It facilitates simple and direct studies of oxidation and annealing kinetics for sputtered thin films.

Furthermore, real time regression analysis of the in situ SE data introduces an easy and precise method for determining thicknesses, growth rates, and optical constants for individual layers in the multilayers or complex multilayer structures. In this article, only $\Psi$ data are presented to reduce the number of figures. 


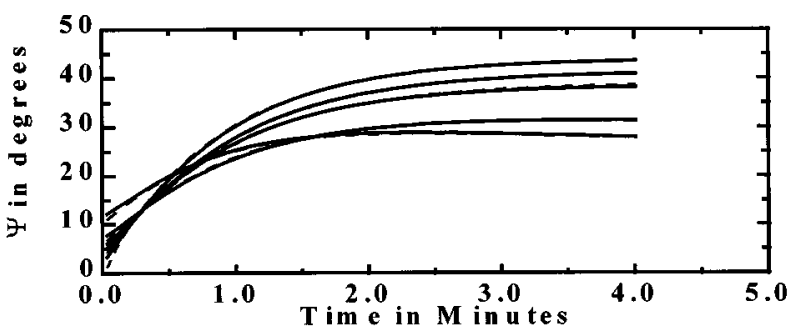

a.

\begin{tabular}{|llr|}
\hline 2 & $\mathrm{Au}$ & Growth rate $=0.251 \pm 0.003 \mathrm{~nm} / \mathrm{sec} \mathrm{nm}$ \\
\hline 1 & $\mathrm{SiO} 2$ & $3.89 \mathrm{~nm}$ \\
\hline 0 & $\mathrm{Si}$ & $1 \mathrm{~mm}$
\end{tabular}

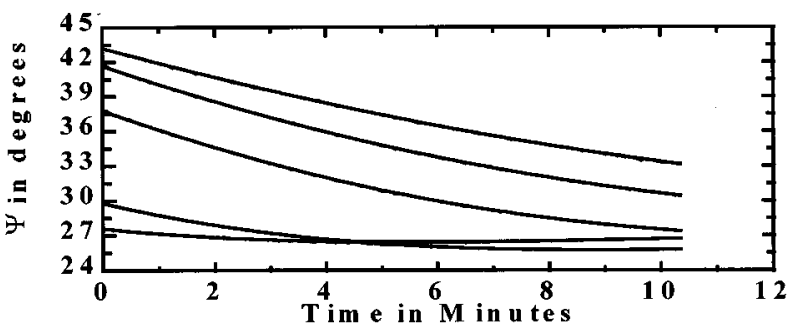

c.

\begin{tabular}{|llr|}
\hline 1 & Co Film & Growth Rate $=0.0254 \pm 0.001 \mathrm{~nm} / \mathrm{sec}$ \\
\hline 0 & Au & $1 \mathrm{~mm}$
\end{tabular}

d.

FIG. 2. (a) In situ $\mathrm{SE} \Psi$ data taken during growth of a $\mathrm{Au}$ film on a $\mathrm{Si}$ substrate, and fitted data using model in (b). (b) Model and fitting results of the growth rate for the experimental data in (a). (c) In situ SE $\Psi$ data taken during growth of a Co film on an optically thick Au underlayer, and fitted data using the model in (d). (d) Model and growth rate for the experimental data in (c). Note: The dotted and solid lines are experimental and fitted SE data, respectively. Wavelengths range from $413.5 \mathrm{~nm}$ to $753.8 \mathrm{~nm}$ from bottom to top (five out of 44 wavelengths are selected for clarity).

\section{RESULTS AND ANALYSIS}

In many respects in situ SE on metallic multilayers differs from studies of dielectrics. We shall illustrate by examples.

\section{A. Determination of the growth rates and thin film optical constants}

Two methods were used to make multilayers with precise layer thickness. The first is as follows. Before making thin multilayers, thicker metal layers were deposited to determine approximate the growth rates and optical constants. The sputter growth rates of metallic films on substrates were thus calibrated by fitting in situ SE data with models simultaneously treating the growth rate, optical constants, and angle of incidence of the input light beam as variables. This was easily done each time a new set of substrates was loaded into the chamber, as oxidation and/or erosion of the sputter target can take place from run to run.

The model fits for SE data taken from growth of $\mathrm{Au}$ on $\mathrm{Si}$ and $\mathrm{Co}$ on $\mathrm{Au}$ are shown in Figs. 2a and 2c, with their respective models in Figs. $2 b$ and $2 d$. The growth rates and optical constants for $\mathrm{Au}$ and $\mathrm{Co}$ in both fits were variables, and are assumed to be constant in time. The fits are excellent,

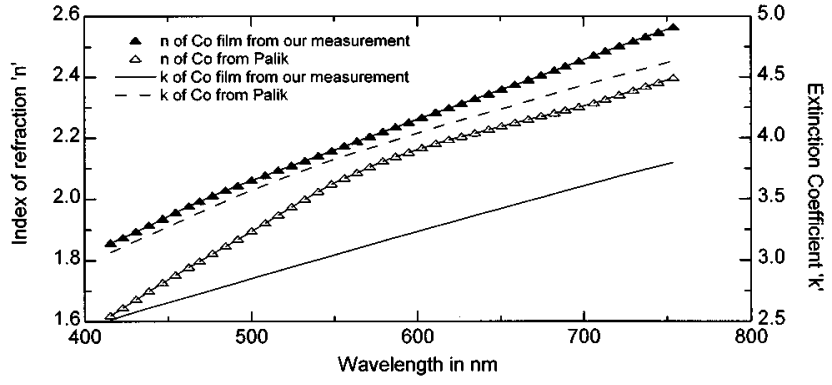

a.

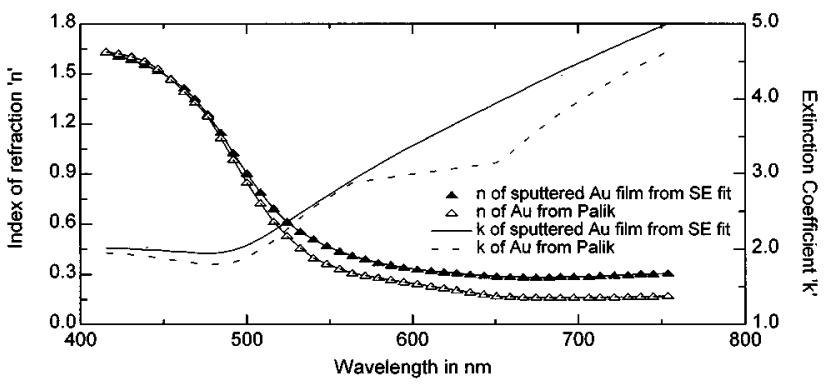

b.

FIG. 3. (a) Comparison of published bulk Co optical constants with results from our SE fit for thin film $\mathrm{Co}$ on a $\mathrm{Au}$ underlayer. (b) Comparison of optical constants of published bulk Au with those from our fit result for thin film $\mathrm{Au}$ on $\mathrm{Si}$.

and the experimental and model derived data overlap with each other. The optical constants obtained from these fits are accurate, due to the fact that the analysis was continuously made at all stages of the growth.

In Figs. 3a and 3b, we compare measured optical constants for $\mathrm{Co}$ and $\mathrm{Au}$ thin film layers, and compare them to published values from Ref. 13. It is clear that the published Au data have an unphysical "kink" in part of the spectral range. ${ }^{13}$

After calibration of the growth rate and determination of the optical constants of a metal film, the growth can then be "controlled" by timing the deposition, then signaling the sputter gun to turn on or off for certain desired thicknesses.

The second way to control layer growth is to take data during deposition and to simultaneously fit the data to a model to obtain the thickness value. It is then possible to have the sputter gun power turn on or off under closed-loop feedback control, a mode we now discuss.

In a closed-loop control example, $\mathrm{Ni}$ films on $\mathrm{Si}$ wafer substrates were deposited by DC magnetron sputtering from a nickel target in a 10 mTorr argon gas environment. The deposition rate of the Ni film was varied between $0.08 \mathrm{~nm} /$ sec and $0.16 \mathrm{~nm} / \mathrm{sec}$ by changing the DC power from $30 \mathrm{~W}$ to $60 \mathrm{~W}$. The data acquisition time was set to $1.5 \mathrm{sec}$. At any time, a straight line fit to the three most recent data points each $1.5 \mathrm{sec}$ apart was used to determine when to turn off the power supply. It should be pointed out that faster data acquisition is not necessary, as the ellipsometer does not need to be acquiring data at the time of power shutdown required for precise thickness control. In our specific chamber it was nec- 


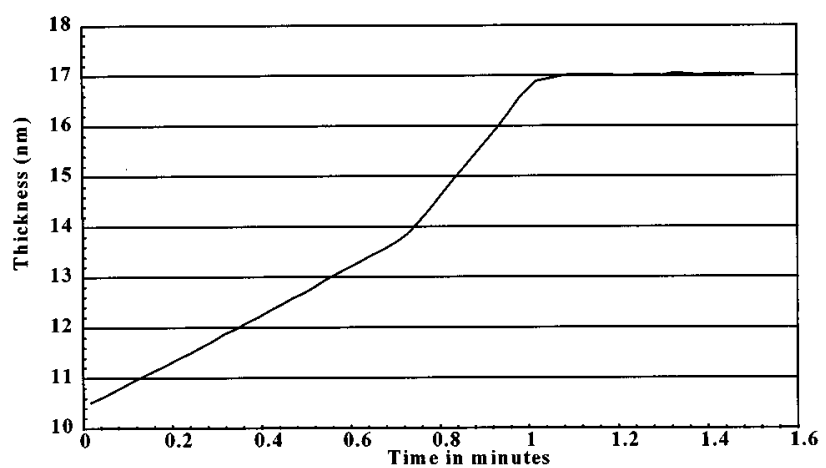

FIG. 4. Closed-loop feedback control of Ni film thickness on a Si substrate: Target thickness set for $17 \mathrm{~nm}$ with a growth rate of $0.08 \mathrm{~nm} / \mathrm{sec}$ for thickness under $14 \mathrm{~nm}$, and deliberately changed to $0.16 \mathrm{~nm} / \mathrm{sec}$ for thickness above $14 \mathrm{~nm}$. The purpose of changing the deposition rate was to demonstrate independent thickness control.

essary to include a turn off transient time $(0.6 \mathrm{sec}$ for the chamber used for these depositions) to account for the time between when the control program signaled the sputter gun to turn off and when it finally shut down.

As shown in Fig. 4, a Ni film with a $17 \mathrm{~nm}$ target thickness was deposited at $0.08 \mathrm{~nm} / \mathrm{sec}$ before the thickness reached $14 \mathrm{~nm}$, and the deposition rate was manually increased to $0.16 \mathrm{~nm} / \mathrm{sec}$ after $14 \mathrm{~nm}$. This was done to test the control program's ability to adapt to changes during deposition. The final thickness was within $0.02 \mathrm{~nm}$ of the target value.

\section{B. Determination of the thicknesses and optical constants in multilayers}

The first procedure described in Sec. III A, that of calibrating the growth rate and timing the deposition, was followed each time by preparation of a new set of eight samples. For example, knowing the growth rates of $\mathrm{Au}$ on $\mathrm{Si}$, $\mathrm{Co}$ on $\mathrm{Au}$, and $\mathrm{Au}$ on $\mathrm{Co}$, permitted choice of the length of time for growing the $\mathrm{Au}$ and Co layers in the multilayers to make a $[\mathrm{Co} / \mathrm{Au}]_{\mathrm{n}} / \mathrm{Au} / \mathrm{Si}$ structure.

Optical contrast of spectrally dependent optical constants between some metals can sometimes be very small, such as between $\mathrm{Co}$ and $\mathrm{Ni}$ or between $\mathrm{Co}$ and $\mathrm{Pd}$. Certain techniques are necessary to distinguish between layers of different metals. For this reason, an in situ SE study of multilayers with both high and with low optical contrast, as well as deposition of a three-layer multilayer structure were undertaken.

\section{Multilayers with high optical contrast-[Co/Au]/Au, $[\mathrm{Co} / \mathrm{Cu}] / \mathrm{Cu}$}

In situ SE data taken from magnetic and non-magnetic multilayer $[\mathrm{Co} / \mathrm{Au}]_{10} / \mathrm{Au}$ and $[\mathrm{Co} / \mathrm{Cu}]_{50} / \mathrm{Cu}$ structures are shown in Figs. 5a and 5b, respectively. These structures and materials are of great importance for giant magnetoresistance, spin-valve and other applications due to the possible control of magnetic exchange coupling between layers. The high optical contrast between $\mathrm{Co}$ and $\mathrm{Au}$ and between $\mathrm{Co}$
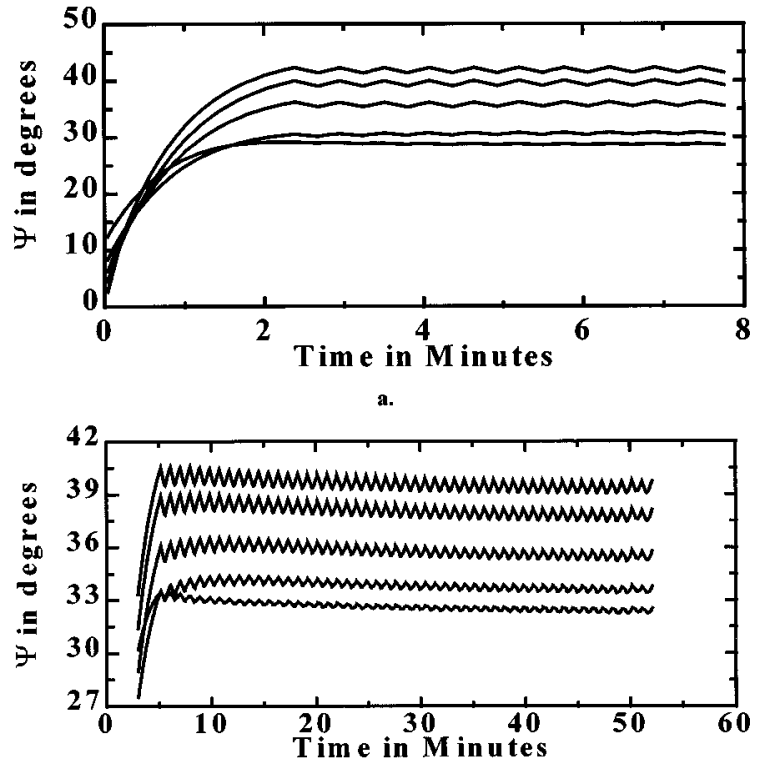

b.

FIG. 5. (a) In situ SE data during deposition of magnetic $[\mathrm{Co} / \mathrm{Au}]_{10} / \mathrm{Au}$. (b) In situ $\mathrm{SE}$ data for magnetic $[\mathrm{Co} / \mathrm{Cu}]_{50} / \mathrm{Cu}$ multilayer structures. Note: Wavelengths range from $413.5 \mathrm{~nm}$ to $753.8 \mathrm{~nm}$ from bottom to top (five out of 44 wavelengths are selected for clarity).

and $\mathrm{Cu}$ makes it easy to distinguish between the two layers from the in situ SE data, as well as to determine the quality of the multilayers.

Two different $[\mathrm{Co} / \mathrm{Au}]_{10} / \mathrm{Au}$ structures with different $\mathrm{Au}$ layer thicknesses are shown in Figs. $6 \mathrm{a}$ and $6 \mathrm{c}$ and the models with fitting results are shown in Figs. $6 \mathrm{~b}$ and $6 \mathrm{~d}$, respectively. In both cases, the underlayer thicknesses and the individual layer thicknesses obtained from the after-growth fits are within $0.1 \mathrm{~nm}$ of the designed thicknesses using the calibrated growth rates.

The optical constants of Co in the multilayer appear to be different from those of the Co film on Au obtained from the fit in Fig. 2 and from published bulk values. ${ }^{13}$ Notice that the thickness of the Co layer is only a few monolayers. The optical constants obtained here are average values for this 0.6 $\mathrm{nm}$ thick layer. They could be affected by the mixture of $\mathrm{Au}$ and Co atoms at the interface and also by the roughness and structural changes of the Co layer due to the lattice constant difference between $\mathrm{Co}$ and $\mathrm{Au}$.

\section{Multilayers with low optical contrast-[Co/Ni]/Au, [Co/Pd]/Au}

Unlike $[\mathrm{Co} / \mathrm{Au}]$, some multilayers contain different materials with low optical contrast, such as $[\mathrm{Co} / \mathrm{Ni}]$ and $[\mathrm{Co} / \mathrm{Pd}]$. The low optical contrast makes it difficult for the regression analysis to locate the interfaces between the different materials. This leads to a relatively large correlation between the floating parameters: thicknesses and optical constants of different layers.

This problem can be solved using three 'tricks.' First, there is a large difference between the growth rates of the different materials. Time during deposition is under the ex- 


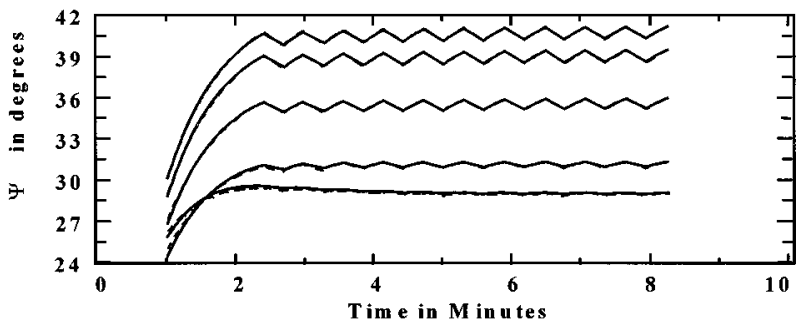

a.

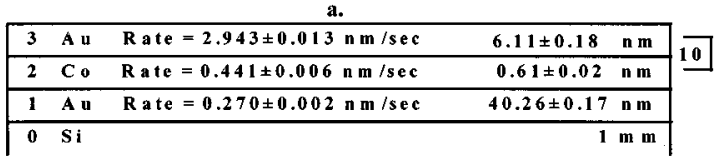

b.

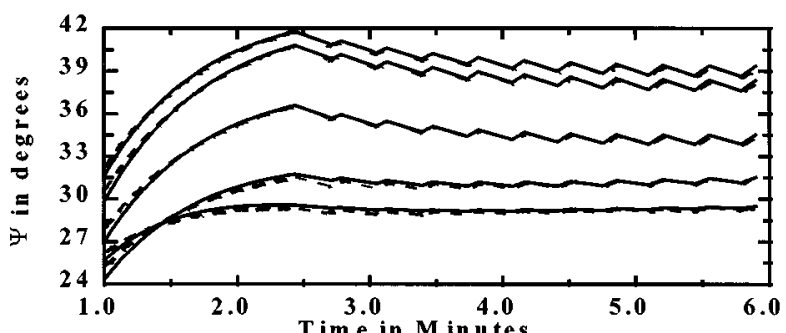

\begin{tabular}{|llr|}
\hline 3 & A U & \\
\hline 2 & Co & $2.00 \mathrm{~nm}$ \\
\hline 1 & A u & $0.60 \mathrm{n} \mathrm{m}$ \\
\hline 0 & Si & $40.24 \mathrm{~nm}$ \\
\hline
\end{tabular}

d.

FIG. 6. (a) Experimental and fitted in situ SE data for a $[\mathrm{Co}(0.6 \mathrm{~nm}) / \mathrm{Au}(6.0$ $\mathrm{nm})]_{10} / \mathrm{Au}$ structure. (b) Model fit results (growth rates and layer thicknesses) for the SE data in (a). (c)Experimental SE data and model fit for a $[\mathrm{Co}(0.6 \mathrm{~nm}) / \mathrm{Au}(2.0 \mathrm{~nm})]_{10} / \mathrm{Au}$ structure. (d)Model fit results (growth rates and layer thicknesses) for the SE data in (c). Note: The dotted and solid lines are experimental and fitted SE data, respectively. Wavelengths range from $413.5 \mathrm{~nm}$ to $753.8 \mathrm{~nm}$ from bottom to top (five out of 44 wavelengths are selected for clarity).

perimenter's control. With a fixed acquisition time $(\sim 1 \mathrm{sec}$ for all 44 wavelengths), the amount of data per unit thickness for the different materials is inversely proportional to their growth rates. Second, the multilayers can be made on semiconductor wafers ( $\mathrm{Si}, \mathrm{GaAs}$, etc.), on transparent substrates (fused silica or glass), or on other materials with much different optical constants from the layer being deposited (for example, $\mathrm{Co}$ or $\mathrm{Ni}$ on $\mathrm{Au}$ or $\mathrm{Cu}$ ). These two procedures produce sufficiently high optical contrast between materials, as long as the layers are "optically thin," so that the light reaches the substrate.

Results using these two "tricks" are demonstrated by the experimental data in Figs. $7 \mathrm{a}$ and $7 \mathrm{c}$ for magneto-optical multilayer structures of $[\mathrm{Co} / \mathrm{Ni}] / \mathrm{Au}$ and $[\mathrm{Co} / \mathrm{Pd}] / \mathrm{Au}$, respectively. The models in Fig. $7 \mathrm{~b}$ and $7 \mathrm{~d}$ were used for fitting these two sets of data, where the floating parameters of the fits were thickness, growth rate, and optical constant. The corresponding calculated data from the fits are also shown in Figs. 7a and 7c with the fitted growth rates and layer thicknesses shown on the model structures in Figs. $7 \mathrm{~b}$ and $7 \mathrm{~d}$, respectively.

The third method to obtain sufficient optical contrast is to

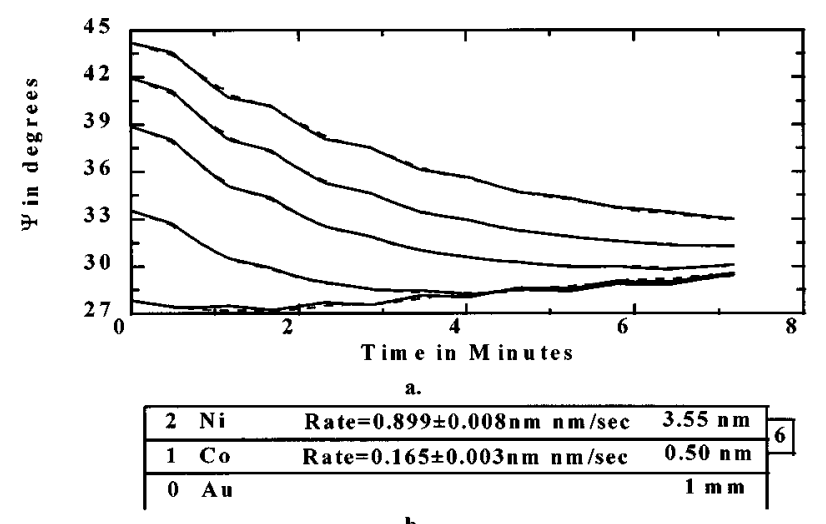

b.

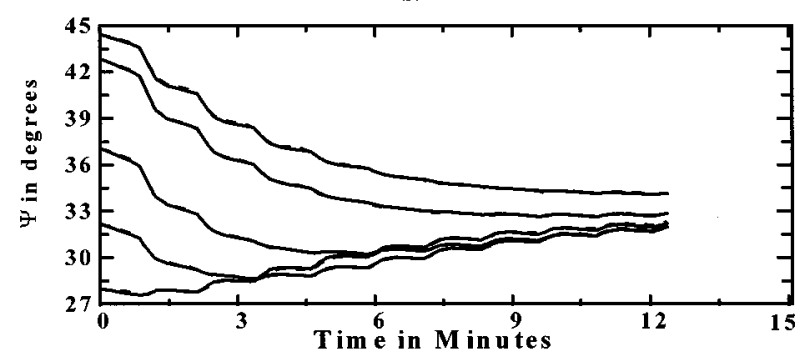

c.

\begin{tabular}{|llrr|r|}
\hline 2 & Pd & Rate $=0.116 \pm 0.004 \mathrm{~nm} / \mathrm{sec}$ & $2.95 \mathrm{~nm}$ & 10 \\
\hline 1 & Co & Rate $=0.017 \pm 0.000 \mathrm{~m} / \mathrm{sec}$ & $0.81 \mathrm{~nm}$ & $1 \mathrm{~m} \mathrm{~m}$
\end{tabular}

d.

Fig. 7. (a) Experimental and fitted $\mathrm{SE}$ data for a $[\mathrm{Co}(0.4 \mathrm{~nm}) /$ $\mathrm{Ni}(3.6 \mathrm{~nm})]_{4} / \mathrm{Au}$ structure. (b) Model fit results (growth rates and layer thicknesses) for the SE data in (a). (c)Experimental data and fitted SE data for a $[\mathrm{Co}(0.8 \mathrm{~nm}) / \mathrm{Pd}(3.0 \mathrm{~nm})]_{10} / \mathrm{Au}$ structure. (d) Model fit results (growth rates and layer thicknesses) for the SE data in (c). Note: The dotted and solid lines are experimental and fitted SE data, respectively. Wavelengths change from $413.5 \mathrm{~nm}$ to $753.8 \mathrm{~nm}$ from bottom to top (five out of 44 wavelengths are selected for clarity).

use a wide range of wavelengths in order to include regions of higher optical contrast. That is, by taking data over a wide spectral range, contrast can usually be found.

\section{Three-constituent multilayer structures}

The in situ SE techniques introduced in Secs. III B1 and B2 were used for controlling the growth of multilayers with three different magnetic and non-magnetic materials. In situ SE data from the magnetic multilayer $[\mathrm{Co} / \mathrm{Pd} / \mathrm{Au}]_{\mathrm{n}} / \mathrm{Au}$ are shown in Fig. 8a. In the initial stages of growth, the optical contrast between $\mathrm{Co}$ and $\mathrm{Pd}$ is higher than that between Co and $\mathrm{Au}$ and that between Pd and Au. This is due to the fact that the multilayer was grown on a $\mathrm{Au}$ underlayer, which makes the first several Au layers difficult to distinguish. On the other hand, the difference in the growth rates for Co and $\mathrm{Pd}$ produced in effect a higher contrast with different $\mathrm{Co}$ and Pd growth rates. This contrast disappears at later times when the multilayer became optically thick. Meanwhile, the contrast produced between $\mathrm{Au}$ and $\mathrm{Co}$ and between $\mathrm{Au}$ and $\mathrm{Pd}$ increases. We were able to obtain a good fit for this set of 


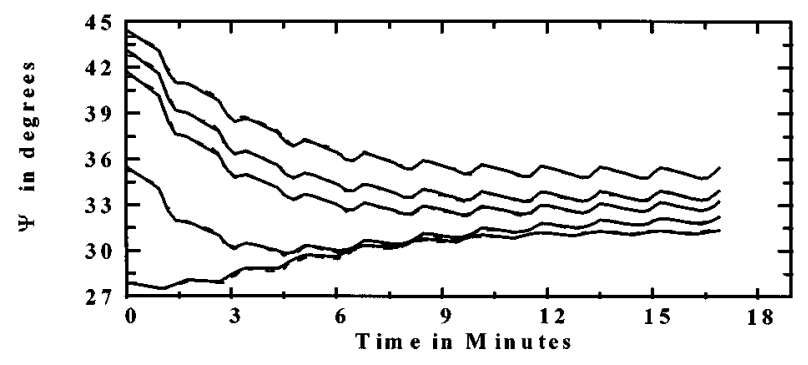

\begin{tabular}{|lllr|}
\hline \multicolumn{4}{c}{ a. } \\
\hline 4 & Au & Rate $=0.081 \pm 0.013 \mathrm{~nm} / \mathrm{sec}$ & $1.94 \mathrm{~nm}$ \\
\hline 3 & Pd & Rate $=0.127 \pm 0.018 \mathrm{~nm} / \mathrm{sec}$ & $2.75 \mathrm{~nm}$ \\
\hline 2 & Co & Rate $=0.022 \pm 0.001 \mathrm{~nm} / \mathrm{sec}$ & $1.15 \mathrm{~nm}$ \\
\hline O & Au & & $1 \mathrm{~mm}$
\end{tabular}

b.

Fig. 8. (a) Experimental and fitted SE data for a $[\mathrm{Co}(1.2 \mathrm{~nm}) / \mathrm{Pd}(2.8 \mathrm{~nm}) /$ $\mathrm{Au}(1.9 \mathrm{~nm})]_{10} / \mathrm{Au}$ structure. (b)Model fit results of growth rates and layer thicknesses. Note: The dotted and solid lines are experimental and fitted SE data, respectively. Wavelengths range from $413.5 \mathrm{~nm}$ to $753.8 \mathrm{~nm}$ from bottom to top (five out of 44 wavelengths are selected for clarity).

data using the model seen in Fig. 8b, and the thicknesses and growth rates of the layers were then determined from the fit.

\section{Oxidation}

Oxidation was studied by taking in situ SE data before and after opening the sputter chamber without moving the sample. In Fig. 9a, the pre-opened and post-opened data taken from a $[\mathrm{Co}(6 \AA) / \mathrm{Au}(60 \AA)]_{50} / \mathrm{Au}$ film overlap with each other. However, fast oxidation was found for the $[\mathrm{Co} /$ $\mathrm{Ni}]_{\mathrm{n}}$ multilayers; in Fig. 9b, we present SE data taken from a $[\mathrm{Co}(4 \AA) / \mathrm{Ni}(35 \AA)]_{50} / \mathrm{Au}$ film before, and up to $36 \mathrm{sec}$ after opening the sputter chamber to the atmosphere. Immediate

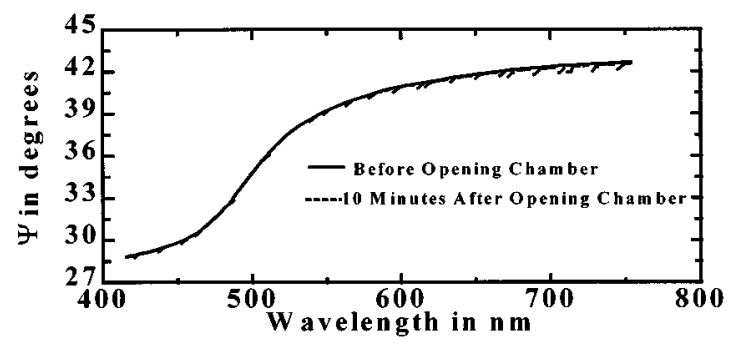

a.

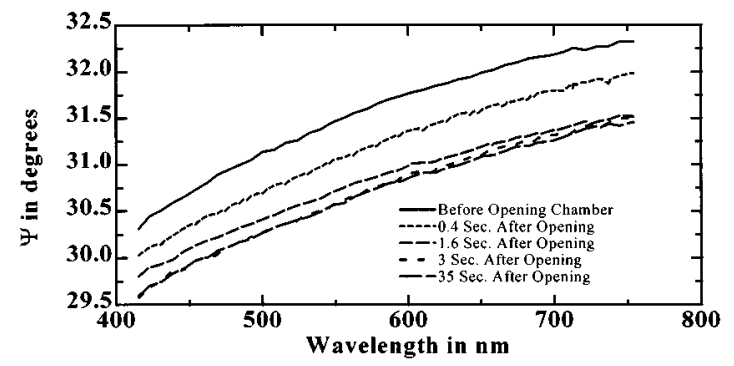

b.

FIG. 9. In situ SE data taken before and after opening the sputtering chamber from (a) $[\mathrm{Co}(0.6 \mathrm{~nm}) / \mathrm{Au}(6.0 \mathrm{~nm})]_{50} / \mathrm{Au}$ and (b) $[\mathrm{Co}(0.4 \mathrm{~nm}) / \mathrm{Ni}(3.6 \mathrm{~nm})$ ]$_{50} / \mathrm{Au}$ multilayer structures.

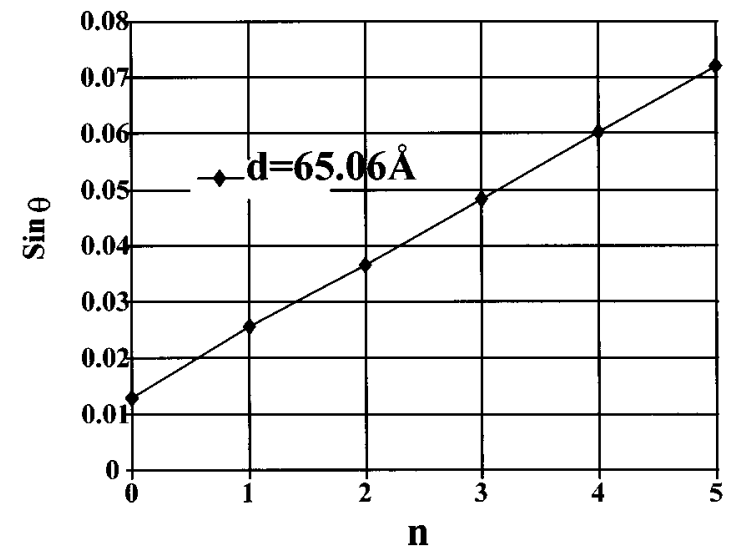

FIG. 10. Small angle $\mathrm{x}$-ray diffraction measurement result for a $[\mathrm{Co}(0.6$ $\mathrm{nm}) / \mathrm{Au}(6.0 \mathrm{~nm})]_{50}$ structure confirming the bilayer thickness determined by in situ $\mathrm{SE}$.

oxidation was found within $0.4 \mathrm{sec}$, and the oxide became relatively stable after about $10 \mathrm{sec}$. It is obvious that oxidation can rarely be studied by removing the sample from the chamber with subsequent attempts at analysis in another location.

\section{X-ray diffraction}

Excellent small angle and high angle XRD patterns were obtained from the $[\mathrm{Co}(6 \AA) / \mathrm{Au}(60 \AA)]_{50} / \mathrm{Au}$ and $[\mathrm{Co}(6 \AA) /$ $\mathrm{Au}(20 \AA)]_{50} / \mathrm{Au}$ films. After analyzing these XRD data, we calculated the $\mathrm{Co}$ and $\mathrm{Au}$ bilayer thicknesses for each of these two multilayers. Fits to the data are shown in Fig. 10. The differences between XRD and the in situ SE results for bilayer thicknesses are smaller than $3 \%$.

\section{SUMMARY}

In situ SE was successfully used for both closed-loop feedback control of layer thicknesses, as well as to calibrate, timed growth of a variety of metallic multilayer structures. $\mathrm{SE}$ is seen to be an easy and non-destructive method to measure layer thicknesses on a subnanometer scale and to determine the optical constants of materials in multilayers as well. In situ SE has the advantage over XRD for layer thickness determination in that individual layer thicknesses can be precisely determined. XRD requires periodic thicknesses in a multilayer. Furthermore, SE provides a powerful and direct method for dynamical study of oxidation of thin film materials.

\section{ACKNOWLEDGMENTS}

The research was supported by the National Science Foundation under Grant Nos. DMR-9623992 and OSR9255225, and by the State of Nebraska funded Center for Microelectronic and Optical Materials Research.

${ }^{1}$ M. N. Baibich, J. M. Broto, A. Fert, F. Nguyen Van Dau, F. Petroff, P. Etienne, G. Creuzet, A. Friederich, and J. Chazelas, Phys. Rev. Lett. 61, 2472 (1988). 
${ }^{2}$ W. F. Eggelhoff, Jr., T. Ha, R. D. K. Misra, Y. Kadmon, J. Nir, C. J. Powell, M. D. Stiles, R. D. McMichael, C.-L. Lin, J. M. Sivertsen, J. H. Judy, K. Takano, A. E. Berkowitz, T. C. Anthony, and J. A. Brug, J. Appl. Phys. 78, 273 (1995).

${ }^{3}$ D. H. Mosca, F. Petroff, A. Fert, and P. A. Schroeder, J. Magn. Magn. Mater. 94, L1 (1991).

${ }^{4}$ A. Chaiken, R. P. Michel, and M. A. Wall, Phys. Rev. B 53, 5518 (1996).

${ }^{5}$ W. A. McGahan and J. A. Woollam, Appl. Phys. Commun. 9, 1 (1989).

${ }^{6}$ C. F. Majkrzak, J. F. Ankner, N. F. Berk, and D. Gibbs, Magnetic Multilayers, edited by L. H. Bennett and R. E. Watson (World Scientific, Singapore, 1994), p. 299.
${ }^{7}$ J. A. Woollam, X. Gao, S. Heckens, and J. N. Hilfiker, Proc. SPIE 2873, 140 (1996).

${ }^{8}$ R. M. A. Azzam and N. M. Bashara, Ellipsometry and Polarized Light (North-Holland, New York, 1977), Chap. 4.

${ }^{9}$ G. E. Jellison, Jr., Appl. Opt. 30, 3354 (1991).

${ }^{10}$ R. W. Collins, Rev. Sci. Instrum. 61, 2029 (1990).

${ }^{11}$ E. A. Irene and J. A. Woollam, MRS Bull. 24 (1995).

${ }^{12}$ B. Johs, C. Herzinger, J. H. Dinan, A. Cornfeld, J. D. Benson, D. Doctor, E. Olson, I. Ferguson, M. Pelczynski, P. Chow, C. H. Kuo, and S. Johnson, Proceedings of the 2nd International Conference on Spectroscopic Ellipsometry; Thin Solid Films (in press).

${ }^{13}$ Handbook of Optical Constants of Solids, edited by E. Palik (Academic, Orlando, 1985), Chap. 5. 